\title{
O NOVO ENSINO MÉDIO DE TEMPO INTEGRAL: REDUCIONISMO, PRIVATIZAÇÃO E MERCANTILIZAÇÃO DA EDUCAÇÃO PÚBLICA EM TEMPOS DE ULTRACONSERVADORISMO
}

\section{THE NEW FULL-TIME HIGH SCHOOL: REDUCIONISM, PRIVATIZATION AND COMMODIFICATION OF PUBLIC EDUCATION IN TIMES OF ULTRACONSERVATISM}

BARBOSA, Carlos Soares ${ }^{1}$

\begin{abstract}
Resumo
O presente artigo é resultado da pesquisa qualitativa e bibliográfica, e tem por objetivo contribuir com as discussões que vêm sendo realizadas nos diversos espaços sociais sobre o novo Ensino Médio de Tempo Integral (EMTI). Além de demonstrar sua dimensão reducionista e como atende aos interesses da classe empresarial no contexto do ultraconservadorismo brasileiro, argumenta que a privatização e a mercantilização da educação pública é um dos pilares de sustentação de nova reforma educacional. Por fim, destaca que o EMTI se orienta no sentido contrário da formação crítica, humana e integral, pois visa tão somente a formação dos trabalhadores demandados pelo atual padrão de acumulação flexível do capital.
\end{abstract}

Palavras-Chave: Ensino Médio de Tempo Integral; Ultraconservadorismo; Acumulação flexível.

\begin{abstract}
This article is the result of qualitative and bibliographic research, and aims to contribute to the discussions that have been held in various social spaces about the new Full Time High School (EMTI). In addition to demonstrating its reductionist dimension and how it meets the interests of the business class in the context of Brazilian ultra-conservatism, it argues that the privatization and commodification of public education is one of the pillars of the new educational reform. Finally, it emphasizes that EMTI is in the opposite direction of critical, humane and integral formation, since it aims only at the formation of workers demanded by the current pattern of flexible capital accumulation.
\end{abstract}

KEYWORDS: Full time high school; Ultraconservatism; Flexible accumulation.

\footnotetext{
${ }^{1}$ Professor Adjunto da Faculdade de Educação da Universidade do Estado do Rio de Janeiro. Doutor em Políticas Públicas e Formação Humana (PPFH/UERJ) e Mestre em Educação (UFRJ). Rio de Janeiro, $\mathrm{Rj}$, Brasil. e-mail: profcarlossoares@gmail.com
} 


\section{INTRODUÇÃO}

O Ensino Médio tem ocupado, nos últimos anos, papel de destaque nas discussões acerca da educação brasileira, principalmente quando os resultados das avaliações institucionais adquirem visibilidade nas mídias, demonstrando que a estrutura, os conteúdos e as condições atuais da última fase da educação básica estão longe de atender às necessidades dos estudantes, tanto nos aspectos da formação para a cidadania como para o mundo do trabalho. Em diversos países, o foco da discussão sobre o Ensino Médio tem se pautado em torno da sua identidade e finalidades. A tensão reside entre a perspectiva democratizante, que defende 0 direito a uma formação geral para todos os jovens brasileiros, e a posição seletiva, que defende a segmentação dos percursos escolares, sobretudo, por ser o ensino médio a etapa da escolarização que imediata e mediatamente se relaciona com a transição para o mundo do trabalho para os jovens das camadas mais pauperizadas da classe trabalhadora.

Por essa razão, a atual reforma do Ensino Médio, exarada inicialmente por meio da Medida Provisória no 746/2016 e transformada na Lei no 13.415/2017, tem mobilizado diferentes atores sociais e divergentes posicionamentos políticos sobre os rumos que essa etapa de ensino deve tomar no país. Expressam a correlação de forças, interesses e expectativas dos sujeitos (individual e coletivo) sobre o tema, com base na posição social em que ocupam na cadeia produtiva. Como toda política, tem se constituído um campo de disputa cujas forças são representadas, de um lado, pelo governo, organismos internacionais e a classe empresarial da educação, a exemplo do Banco Mundial, o Movimento Todos pela Educação, Instituto Ayrton Senna, Instituto Unibanco, Fundação Lemann; e do outro, estudantes, profissionais da educação, pesquisadores e suas organizações representativas e associações científicas, além de uma intelectualidade orgânica de esquerda, contra-hegemônica ao projeto conservador ora no poder - economicamente ultraliberal e politicamente ancorado em práticas fascistas e fundamentalistas. Os debates nas audiências públicas, seminários, fóruns e congressos ocorridos em todo país durante o trâmite da Lei tornaram público o projeto de educação nacional defendido pelas principais frações de classes no atual padrão de acumulação do capital no país.

Ademais, a cerrada campanha que o MEC e seus apoiadores passaram a fazer nos principais e distintos aparelhos midiáticos do país com o intuito de construir o consenso em torno da necessidade da "reforma" desvela as estratégias utilizadas para o convencimento da maioria, isto é, o uso de um discurso apologético, baseado na relação causal e linear entre qualificação e inserção no mercado de trabalho, que promete um caminho rumo ao sucesso e repleto de possibilidades e escolhas.

Os argumentos utilizados pelo Governo Temer e seus aliados para justificar a urgência e a necessidade da reforma são de que o vigente Ensino Médio é extenso, superficial e fragmentado, não despertando o interesse dos jovens, nem favorecendo 
a aprendizagem e o desenvolvimento das competências necessárias para a vida social do novo milênio. Na concepção do governo e seus apoiadores, a consequência desse processo é o baixo desempenho dos estudantes em Língua Portuguesa e Matemática no Sistema de Avaliação da Educação Básica (SAEB) e no Programa Internacional de Avaliação de Alunos (PISA) (BRASIL, 2016). Limitando o problema da educação as questões curriculares a "solução" apresentada consiste em criar uma nova matriz curricular, organizando-a em disciplinas obrigatórias e optativas. No caso brasileiro, por uma Base Nacional Comum Curricular (BNCC) e por uma parte diversificada constituída por cinco itinerários formativos.

Seguindo o enfoque adotado pela Unesco e pelo PISA, a BNCC focaliza as expectativas de aprendizado em Português e Matemática (únicas disciplinas obrigatórias nos três anos) e privilegia o desenvolvimento de competências, com base nos quatro pilares descritos no Relatório Delors - aprender a conhecer, aprender a fazer, aprender a viver juntos e aprender a ser. No documento da BNCC, competência é definida como "a mobilização de conhecimentos (conceitos e procedimentos), habilidades (práticas, cognitivas e socioemocionais), atitudes e valores para resolver demandas complexas da vida cotidiana, do pleno exercício da cidadania e do mundo do trabalho" (BRASIL, 2017, p.8), que possibilite o protagonismo juvenil e a construção de um projeto de vida do aluno, conforme mencionado no $\S 7^{\circ}$ do Art. $3^{\circ}$ da Lei 13.415/2017.

Como buscaremos argumentar nesse texto, o novo Ensino Médio é a expressão do projeto de formação reducionista, pragmática e interessada a ser destinada aos jovens das classes trabalhadoras, e do projeto de privatização/mercantilização da educação pública forjado no golpe político, jurídico e midiático, que culminou com o impeachment da presidente Dilma Roussef, em maio de 2016. Projeto este, que no atual governo Bolsonaro adquire contornos mais dramáticos, tendo em vista o aumento da pobreza, do desemprego, do ataque aos direitos, da redução dos gastos com as políticas sociais e da adoção por parte do MEC de medidas obscurantistas, autoritárias, persecutórias e de desmontagem da política nacional de educação com a redução do financiamento federal.

Face a essas considerações iniciais e a partir da identificação da direção moral e intelectual do novo Ensino Médio, o objetivo deste texto é contribuir com as discussões que vêm sendo feitas sobre a reforma educacional, doravante chamada de contrarreforma por configurar um ataque ao direito a educação de qualidade para todas as pessoas, instituída de forma apressada e autoritária, sem considerar os argumentos dos que se encontram no chão da sala de aula. Dentre as muitas mudanças instituídas pela Lei 13.415/2017, focaremos nossa análise no novo Ensino Médio de Tempo Integral (EMTI). Para os objetivos aqui delineados, este texto segue a seguinte estrutura: no primeiro momento retrataremos a dimensão reducionista do EMTI e como ele atende aos interesses da classe empresarial. Em seguida situaremos a contrarreforma educacional no contexto ultraconservadorismo 
brasileiro, demonstrando que a privatização e a mercantilização da educação pública é um dos seus pilares de sustentação.

\section{DimenSÃo REDUCIONISTA, PRAGMÁtiCA E INTERESSADA DO NOVO EMTI}

São muitos os aspectos do novo Ensino Médio que demarcam o reducionismo da formação para as classes trabalhadoras, a começar pela carga horária destinada a BNCC, que não poderá ultrapassar a 1.800 horas. Isso corresponde a menos 600 horas da carga horária do atual Ensino Médio propedêutico, que é de 2.400 horas, e será inferior a $50 \%$ da carga horária total, de 4.200 horas para os três anos, depois que ela for integralmente implementada. Reduzir a carga horária da base comum curricular significa negar o que é o comum na educação básica, cerceando os jovens das classes populares ao acesso ao conhecimento sistematizado produzido historicamente pela humanidade, já que, para muitos deles, a escola se constitui no principal espaço de acesso a esse conhecimento. Cabe reconhecer que "a inclusão na sociedade contemporânea não se dá sem o domínio de determinados conhecimentos que devem ser assegurados a todos" (BRASIL, 2011, p. 25).

Ademais, os itinerários formativos deverão ser organizados "conforme a relevância para o contexto local e a possibilidade dos sistemas de ensino" (BRASIL, 2017). Como deixa claro o texto da lei, nem todas as escolas selecionadas pelas redes de ensino para fazer parte do EMTI serão obrigadas a oferecer todos itinerários. Considerando a carência de professores que há em alguns componentes curriculares, as redes tenderão a não oferecer os itinerários formativos propedêuticos que correspondam às áreas de maior carência de docentes. Portanto, os estudantes não terão muita possibilidade de escolha, conforme foi divulgado nas propagandas financiadas pelo governo federal e veiculadas nos principais aparelhos da mídia comercial com o intuito de conquistar o consenso ativo/passivo dos estudantes e de seus familiares à reforma.

Em contrapartida, devido à falta de professores em alguns componentes curriculares as redes poderão ser levadas a priorizar a formação técnica e profissional, mediante a autorização de se contratar profissionais com "notório saber" para atuar nesta área da formação. Essa parece ser a real intenção, com base na exposição de motivos do ministro da educação à época do envio da MP ao Congresso Nacional e nos argumentos de seus aliados proferidos nas audiências públicas. Entre os motivos apresentados pelo ministro Mendonça Filho, a não qualificação dos jovens para o mercado de trabalho é um dos problemas que precisa ser enfrentado pelo novo Ensino Médio, tendo em vista que apenas $10 \%$ das matrículas estão na Educação Profissional. Percebe-se, assim, que os elaboradores da reforma e seus apoiadores vislumbram muito mais a formação do futuro empregado do que a formação humana e integral. Isso se explicita na flexibilização da oferta da formação técnica e profissional, que poderá ser feita em módulos, à 
distância, por meio de convênios com instituições escolares ou não, e por certificação de competências adquiridas em experiências de trabalho ou em cursos oferecidos "por centros ou programas ocupacionais" (BRASIL, 2017).

Retoma-se, assim, o caráter instrumental e pragmático da política educacional instituída na Reforma Capanema, na Lei no 5692/71, nas proposições do Dec. no 2208/97 e das DCNEM, de 1998, o de adequar a educação às mudanças do setor produtivo e preparar os jovens para a flexibilização das relações de trabalho (FERRETI; SILVA, 2017). Orienta-se, assim, conforme a lógica da função da educação formal na sociedade capitalista defendida pelo capital: "fornecer os conhecimentos e o pessoal necessário à maquinaria produtiva em expansão do sistema capitalista, mas também gerar e transmitir um quadro de valores que legitima os interesses dominantes" (MÉSZÁROS, 2014, p.15). E como toda ação educativa está atrelada a determinada(s) intencionalidade(s), no atual contexto brasileiro de ultraconservadorismo econômico e cultural instituído após o golpe de 2016, o projeto ético-político do novo EMTI não visa a assegurar aos jovens o acesso ao conhecimento historicamente acumulado e a produção coletiva de novos conhecimentos, com o intuito de possibilitá-los a expandir seus horizontes e dotá-los de autonomia intelectual, mas formar o sujeito apolítico, acrítico e adaptável às mudanças do mercado, desenvolvendo as competências exigidas pela nova configuração do mundo do trabalho.

De acordo com as orientações dos organismos internacionais (Unesco, OCDE, Banco Mundial) cabe a educação desenvolver um conjunto de competências que os possibilite a enfrentar os desafios do século XXI. Para que sejam bem sucedidos em um mundo marcado por desenraizamento, instabilidade e incertezas, além das competências técnicas e cognitivas é preciso o desenvolvimento de competências comportamentais e socioemocionais, isto é, a "capacidade de atingir objetivos, de trabalhar eficientemente em grupo e de lidar com as emoções" (OCDE, 2015). Esse é o sentido do estímulo ao protagonismo juvenil e a construção de um projeto de vida pelo novo Ensino Médio, conforme mencionado no $\S 7^{\circ}$ do Art. $3^{\circ}$ da Lei 13.415/2017. Atitudes necessárias para a postura de naturalização diante do aumento da taxa de desemprego no Brasil e, consequentemente, para a indução ao empreendedorismo como alternativa de sobrevida no contexto da "crise da sociedade salarial" (CASTEL, 1999), sobretudo da população juvenil.

No Brasil, nas últimas três décadas, o empreendedorismo vem sendo apresentado como "a" solução para enfrentar o desafio do desemprego, tratando-o como uma questão de ordem individual e não como produto do sistema capitalista, que com a reestruturação produtiva e no atual regime de acumulação do capital tem colocado milhares de trabalhadores a deriva, em situação de "desalento" (que não tem emprego e desistiram de procurar) e/ou abaixo da linha da pobreza. Com a retomada do ultraconservadorismo econômico neoliberal no pós-golpe e a crescente degradação das condições objetivas de produção e reprodução da existência de 
milhares de trabalhadores, podendo vir a incidir em convulsões sociais como a que levou milhares de jovens brasileiros as ruas em junho de 2013, é preciso reorganizar a educação com vista a se retomar suas finalidades de controle social, socialização, conformação social e de total adequação aos ditames do mercado.

Para essa formação interessada ao capital é preciso uma reforma em toda a educação básica, que no caso do Ensino Médio significa reduzir o conteúdo científico, a criatividade e o pensamento crítico, retirando a obrigatoriedade das disciplinas de Sociologia, Filosofia, Arte e Educação Física, e reduzindo a carga horária/conteúdo das demais ciências, agora reagrupadas em áreas do conhecimento (Ciências da Natureza e suas Tecnologias e Ciências Humanas e Sociais Aplicadas), podendo ser tratadas em um ano ou dois, conforme a organização do currículo a ser definido por cada sistema de ensino. Soma-se a esse aspecto, no governo Bolsonaro, a guerra ao que chamam de marxismo cultural e o combate ao conjunto de questões a ele associado, como a educação emancipatória, a denúncia do racismo, o respeito à diversidade, a igualdade de gênero, o combate à pobreza e a defesa dos direitos humanos. Significa também romper a perspectiva da educação integral, conforme preconizada na DCNEM de 2012, reafirmando a dualidade estrutural de ensino e a fragmentação entre o pensar e o fazer; além de formar o trabalhador de acordo com os postos e a hierarquização da cadeia produtiva, seguindo a lógica da "polarização de competências" (KUENZER, 2000).

De acordo com as normativas da Portaria MEC no 1.145/2016 (BRASIL, 2016a), redefinidas pela Portaria MEC no 727/2017 (BRASIL, 2017a), a adesão dos Estados e Distrito Federal ao Programa de Fomento à Implementação das Escolas em Tempo Integral, principal ação no Governo Temer para indução da ampliação da jornada escolar nas escolas públicas, dar-se-á por meio da assinatura do Termo de Compromisso e Elaboração do Plano de Implementação. Entre outras providências, a Portaria definiu o número máximo de 572 escolas e de 257.400 matrículas, em termo nacional, assim como o quantitativo mínimo de alunos e de escolas para cada Unidade da Federação, tendo como base os princípios de representatividade e abrangência das matrículas nas redes públicas. Quantidade pouco expressiva se tomamos como referência as unidades escolares que participaram do Programa federal Ensino Médio Inovador (ProEMI), iniciado no Governo Lula da Silva, em 2009, e desenvolvido até 2018 em parceria com as secretarias de Estado de Educação. 0 que não deixa ser um alento, já que a concepção de educação integral nos documentos que normatizam a reforma é totalmente distinta dos pressupostos filosóficos, epistemológicos e pedagógicos defendidos pelos teóricos da matriz histórico-crítica.

Na Lei no $13.415 / 2017$ e na Portaria MEC no 1.145/2016 constatam-se uma prática recorrente na agenda de educação integral no Brasil, que é a de confundir propositalmente o conceito de educação integral com o de escola de tempo integral, enfatizando o tempo ampliado em detrimento da formação integral. Tendo em vista 
que a ampliação do tempo diário de trabalho escolar não implica, necessariamente, formação integral, para Silva e Boutin (2018) a formação integral e integrada parece estar em segundo plano, posto que não é o tempo ampliado que está em prol da educação integral, mas ao contrário, a educação dita integral parece ser uma manobra para contemplar o tempo ampliado. Nesse sentido, em diálogo com Cavalliere (2009), é preciso questionar a concepção de escola de tempo integral que tem mobilizado os planejadores da reforma. Trata-se de uma concepção de escola, ou da ocupação de alunos carentes em tempo integral para evitar sua marginalidade? Ou seria uma estratégia de controle social conferida ao novo Ensino Médio, como ressaltam Motta e Figotto (2017)?

Para Junckers (2016), no Brasil,

A escola pública de tempo integral tem como centralidade o aumento do tempo das crianças pobres e desamparadas socialmente, sob responsabilidade do poder público, e desta forma, visa atender suas necessidades básicas de saúde (alimentação, higiene, atividade física) e educação (moral, civil, profissional). Tais características levam a reflexão sobre o ideal formativo posto, de ampliação das oportunidades de aprendizagem, em detrimento de um atendimento precarizado, sem investimento financeiro na estrutura física e pedagógica da escola, quando destinada à classe popular (JUNCKES, 2016, p. 12).

Trata-se, assim, de concepção de educação integral que vai de encontro aos pressupostos filosóficos, epistemológicos e pedagógicos defendidos pelos teóricos da matriz histórico-crítica, a saber: formação científico-tecnológica, fundamentada na integração curricular em torno dos eixos do trabalho, ciência, tecnologia e cultura a fim de promover nos jovens a compreensão crítica do trabalho e da sociedade, levando-os a uma ação política com vista à desalienação e a transformação social. Formação pautada no trabalho como princípio educativo, a pesquisa como princípio pedagógico, os direitos humanos como princípio norteador e a sustentabilidade ambiental como meta universal (BRASIL, 2011). Uma formação com base unitária, que viabilize a apropriação do "conhecimento e desenvolvimento de métodos que permitam a organização do pensamento e das formas de compreensão das relações sociais e produtivas, que articule trabalho, ciência, tecnologia e cultura na perspectiva da emancipação humana" (BRASIL, 2011a, p. 29).

O processo de implementação da reforma, em sentido lato, e do currículo, em sentido stricto, configura uma nova arena de disputa política, instigando a resistência de professores, estudantes e pesquisadores comprometidos com a educação pública de qualidade para todos. Nessa perspectiva, cabe aos setores progressistas a construção de uma agenda única que tenha, entre outros pontos, a defesa da escola 
DOI: $10.12957 /$ e-mosaicos.2019.46449

pública, laica e republicana, opondo-se frontalmente aos projetos de mercantilização e privatização da educação.

\section{Privatização/mercantilização da educação Pública: O novo Ensino Médio NO CONTEXTO DO ULTRACONSERVADORISMO ECONÔMICO, POLÍTICO E CULTURAL}

O interesse da classe empresarial com a flexibilização da nova matriz curricular não se restringe em formar os trabalhadores demandados pelo atual padrão de acumulação do capital. A ganância dos empresários do setor educacional direciona-se para as possibilidades de lucros que as parcerias público-privadas (PPP) podem proporcionar, seja como forma de "contornar" a infraestrutura insatisfatória da maioria das escolas públicas para realização da formação técnica e profissional, seja no oferecimento de serviços de consultoria e pacotes de formação continuada aos professores da rede, inclusive na modalidade a distância. O passo estratégico para que as PPPs possam ser custeadas com recursos do FUNDEB foi dado pela Lei no $13.415 / 2017$, que também instituiu as mudanças na principal política pública de financiamento da educação.

O projeto de mercantilização das IES públicas - materializado pelo crescente desfinanciamento do governo federal e por projetos como o Future-se - possui relação orgânica com o projeto de educação básica, reducionista e instrumental, defendido pelas principais frações da classe dominante. Tendo em vista que a redução de conteúdos na BNCC não proporcionará as ferramentas conceituais e intelectuais necessárias para aprovação nos exames de ingresso para o Ensino Superior público, a reforma incidirá no incremento das matrículas no Ensino Superior privado, constituindo-se em estratégia para minimizar a crise em que as IES privadas se encontram, e de contenção das camadas populares as IES públicas, tais como os propósitos da Lei no 5.692/71 instituída no governo civil-militar (CUNHA, 2017). Orientando-se na direção oposta das recentes políticas de inclusão escolar e universitária, a reforma aponta para a maior parte da população o Ensino Médio como etapa de conclusão dos estudos - independente da vontade dos estudantes. Deduz-se, portanto que a redução de custos do Estado, a mercantilização e a privatização, engendradas pela transferência de recursos da educação pública para o setor privado, são alguns dos pilares de sustentação da reforma. Daí ter sido forjada por um grupo restrito ligados fortemente aos interesses privatistas, o que tenderá a aprofundar as desigualdades escolares.

Apesar de o Ensino Médio ser direito da população de 15 a 17 anos desde a aprovação da EC 59/2009, ele está bem distante da universalização. Um dado preocupante indicado no Censo Escolar é a redução do quantitativo de matrículas no Ensino Médio a nível nacional, no período de 2013 a 2018. De acordo com Silva (2018), há no Brasil cerca de 10,5 milhões de jovens de 15 a 17 anos, dos quais um pouco mais da metade (51\%) está no Ensino Médio, três milhões (28,5\%) estão no 
Ensino Fundamental e dois milhões não têm nenhum vínculo escolar. Visando corrigir o percentual de alunos que ainda não acessaram o Ensino Médio, o Plano Nacional de Educação (PNE) (2014-204) previu, entre outras metas, que até 2016 esse nível de ensino fosse universalizado para a população de 15 a 17 anos, com a taxa líquida de matrículas devendo chegar a $85 \%$ no fim de sua vigência (BRASIL, 2014). Entretanto, a EC 95/2016 e o novo Ensino Médio comprometem significativamente que essa meta e tantas outras estabelecidas pelo PNE sejam cumpridas.

Todavia, cabe ressaltar que o processo de construção e reformulação curricular não se faz isento das relações de poder e de disputas políticas e ideológicas, uma vez que a discussão sobre currículo é, per si, a discussão sobre o tipo de ser humano, cidadão e de profissional que se pretende formar, bem como o tipo de sociedade que se pretende construir. Toda política e reforma curricular estão imersas na correlação de forças existentes na sociedade e atreladas a interesses políticos e econômicos. Uma análise da especificidade brasileira dos tempos atuais e da historicidade do processo de aprovação da Lei no 13.415/2017 nos ajuda a compreendê-la na totalidade das mudanças efetuadas e no conjunto das mediações que a determinam; isto é, enquanto parte de um projeto político e societário forjado pelos grupos neoliberais e neoconservadores após a derrota nas eleições para 0 governo federal, em 2014, e colocado em prática com o golpe de 2016.

No aspecto político, a especificidade histórica do Brasil é de indeterminação e de incerteza quanto à sobrevida do Estado de direito, aos valores democráticos e à garantia dos direitos essenciais para a reprodução coletiva da existência humana. Não se trata, na verdade, de um fenômeno exclusivamente brasileiro, como demonstram a onda populista de extrema-direita na Europa e o recente governo norte-americano de Donald Trump, não obstante ventos de mudanças comecem a se anunciar na Argentina e no Chile na resistência popular aos efeitos do neoliberalismo. Levitsky e Ziblatt (2018) ressaltam que atualmente as democracias não morrem por meio de golpe militar e pelas mãos de generais, mas por ação de líderes eleitos que promovem a escalada do autoritarismo através do enfraquecimento lento e constante das instituições críticas. Não seria este 0 atual contexto brasileiro - governo Bolsonaro - no qual se verifica a crescente perseguição política e restrição orçamentária dirigidas às universidades públicas, bem como a cooptação/transmutação de instituições que antes serviam para salvaguardar a Constituição e refutar todo tipo de ameaça às garantias constitucionais? Não é este o contexto brasileiro, caracterizado pela criminalização dos movimentos sociais e o crescimento de movimentos antidemocráticos, a exemplo do Escola Sem Partido?

O não apreço a democracia, ao diálogo e a diferença de pensamento já se evidencia desde o início do governo Temer através das mudanças na composição do MEC, exoneração de 12 dos 24 membros do CNE, dissolução do Fórum Nacional de Educação (FNE) e a edição da MP - instrumento com força de lei, adotado pelo presidente da República em casos de relevância e urgência, e com efeitos imediatos - 
para a reforma da educação, que desconsiderou todo o acúmulo das discussões sobre a BNCC que vinham sendo realizadas de forma colaborativa entre a sociedade civil organizada e o Congresso Nacional. Essas ações, ao mesmo tempo em que desvelam o objetivo de interditar o debate público e silenciar as vozes contra hegemônicas ao seu projeto educacional, indicam que a educação cumpre importância estratégica para o projeto político e societário em execução, caracterizado pelo ultraconservadorismo econômico, político e cultural.

$\mathrm{O}$ aspecto econômico do ultraconservadorismo ganha materialidade com a retomada da ortodoxia neoliberal em nome do superávit primário e com a implementação de um conjunto de reforma visando conter os gastos públicos com as políticas sociais (EC no 95/2016) e garantir ao capital as condições estruturais necessárias para o aprofundamento do processo de acumulação (Lei da Terceirização - Lei no 13.429/2017 e a reforma trabalhista - Lei no 13.467/2017). Tais reformas ocorreram no melhor modelo corporativo-jurídico, sem qualquer tipo de discussão com a sociedade civil e à revelia das manifestações coletivas, agradando apenas à elite empresarial e financeira. Do mesmo modo ocorreu com a reforma do Ensino Médio, exarada inicialmente por meio de uma Medida Provisória, à revelia das manifestações de estudantes, professores e pesquisadores do campo da educação contrários ao autoritarismo e a urgência do governo e do MEC quanto aos procedimentos adotados.

No campo cultural, o obscurantismo e ultraconservadorismo se revelam na exclusão do documento da BNCC de questões relacionadas à diversidade, gênero, raça, sexualidade e desigualdade socioeconômica - temas essenciais para as diversas áreas de conhecimento. Tal exclusão revela, ainda que de forma implícita, que a implementação da "escola da mordaça" começa a se configurar nos documentos oficiais, conforme as recomendações do Movimento Escola Sem Partido. Coadunando cultura autoritária, conservadorismo e fundamentalismo religioso (FRIGOTTO; FERREIRA, 2019), os ultraconservadores, retomando os princípios do governo civilmilitar (1964-1985), buscam silenciar professores e destituir o conhecimento escolar como instrumento de consciência critica dos sujeitos com vista à transformação de si e de sua realidade sócio-histórica. Eis a razão das campanhas contra o educador Paulo Freire e o PL que intenta revogar a Lei $n^{\circ} 12.612 / 2012$, que confere ao filósofo e educador pernambucano o título de patrono da educação brasileira.

Pelo exposto, a reforma proposta não ataca o problema da qualidade social do Ensino Médio. A redução de disciplinas e o enxugamento dos conteúdos sinalizam que o objetivo é, na verdade, reduzir a formação crítica das novas gerações, conformando-as para as "ocupações irregulares e eventuais" (MARX, 1998, p. 746), com atividades laborais extensas e de baixo valor agregado que se abrem como principais possibilidades de ingresso dos jovens das camadas populares no mercado de trabalho, a exemplo do trabalho intermitente, contratos por tempo determinado e precarização revestida de estágio. Acrescenta-se o objetivo de vincular os processos 
educativos às avaliações em larga escala, sem problematizar o pouco investimento com a formação docente, a precária infraestrutura e as condições de trabalho vivenciadas pelos professores na maioria das escolas públicas. A intenção é destituir o sentido da "educação como um ato político" (FREIRE, 1982) e impedir a formação de intelectuais orgânicos dos trabalhadores, na perspectiva de Gramsci (1995).

Com o novo Ensino Médio retoma-se a visão minimalista da formação escolar a ser destinada aos jovens trabalhadores, que tenderá a intensificar a dualidade estrutural da educação brasileira e aumentar o apartheid social. E por ser um campo de disputa, o presente projeto de pesquisa se posiciona na luta pela (re)criação da educação integral fundamentada nos pressupostos teóricos aqui referenciados. Ainda que a educação escolar não tenha autonomia para resolver as mazelas produzidas pelo sistema do capital, reconhecemos que a escola pode ampliar as condições de inclusão social ao possibilitar o domínio de saberes qualificadores para uma intervenção social de forma mais consciente e mais autônoma. Por se encontrar imersa no conflito de interesses presentes na sociedade, há na escola espaços de resistências e de ações contra-hegemônicas, possuindo, assim, papel relevante para a transformação social.

\section{CONSIDERAÇões Finais}

O que se coloca em projeção é um esvaziamento cada vez maior da escola para estudantes no Ensino Médio, no caso, a escola pública, ou seja, aquela a que estão destinados amplos segmentos das classes trabalhadoras deste país, o que por certo se constituirá também num progressivo afastamento dos mesmos do Ensino Superior, cujos filtros hoje já estão colocados, ainda que tenham tidos seus efeitos minimizados pelas políticas afirmativas ainda em curso. Comparando-se com as experiências profissionalizantes provenientes da Lei n. 5692/71, essa estratégia é ainda mais excludente porque reduzirá os efeitos de uma trajetória escolar potencializadora dos desejos e de possibilidades de intervenções sociais mais consistentes com maiores chances de ampliação do papel destes sujeitos na realidade em que vivem.

Por fim, é preciso chamar atenção para o fato de que a atual reforma do Ensino Médio, disfarçada de inovadora, renovadora e libertadora, na verdade, esconde o aprofundamento de um terrível processo de esvaziamento da escola por dentro da própria escola, através dos fundamentos da educação como o currículo, a avaliação etc., imperativos de um processo de acumulação flexível do capital que rapidamente delineia ações concretas na conformação na força de trabalho, como aponta Silva (2014, p. 180), reforçando a tendência apontada por Frigotto (2001, p. 83) de extirpar-se da ciência do trabalho comum, de modo a aprofundar a exploração do trabalho alienado. 
Trata-se, portanto, de conformar os jovens trabalhadores as relações precarizadas de trabalho, a exemplo da terceirização e dos trabalhos intermitentes, legalizados indiscriminadamente no Governo Temer por meio da Lei da Terceirização (Lei $n^{\circ} 13.429 / 2017$ ) e da reforma trabalhista (Lei $\left.n^{\circ} 13.467 / 2017\right)$. Ou estimulá-los ao empreendedorismo, em que se faz necessário o desenvolvimento de um conjunto de competências, como iniciativa, resiliência, persistência, resolução de problemas, organização e planejamento. Daí o estímulo ao protagonismo juvenil e a construção de projeto de vida pelo novo Ensino Médio, que se assenta em princípios há certo tempo defendidos pelas organizações empresariais.

\section{REFERÊNCIAS}

BRASIL. Base Nacional Comum Curricular - Ensino Médio. Ministério da Educação. Documento homologado pela portaria no 1570, Diário Oficial da União, Brasília-DF, Seção 1, p.146, de 21 de dezembro de 2017.

BRASIL. Ministério da Educação. Portaria no 727, de 13 de junho de 2017. Estabelece novas diretrizes, novos parâmetros e critérios para o Programa de Fomento às Escolas de Ensino Médio em Tempo Integral - EMTI, em conformidade com a Lei no 13.415, de 16 de fevereiro de 2017. Diário Oficial da União, Brasília, 14 jun. 2017, no 113, seção 1 .

BRASIL. Lei no 13.415, de 16 de fevereiro de 2017. Altera as Leis nos 9.394, de 20 de dezembro de 1996, que estabelece as diretrizes e bases da educação nacional, e 11.494, de 20 de junho 2007, que regulamenta o Fundo de Manutenção e Desenvolvimento da Educação Básica e de Valorização dos Profissionais da Educação, e institui a Política de Fomento à Implementação de Escolas de Ensino Médio em Tempo Integral.

BRASIL. Ministério da Educação. Portaria no 1.145, de 10 de outubro de 2016. Institui o Programa de Fomento à Implementação de Escolas em Tempo Integral, criada pela Medida Provisória no 746, de 22 de setembro de 2016. Diário Oficial da União, Brasília, DF, 11 out. 2016. Seção 1.

BRASIL. Medida Provisória no 746, de 22 de setembro de 2016. Exposição de Motivos. Brasília, DF: Câmara dos deputados. Disponível em: <http://www2.camara.leg.br/legin/fed/medpro/2016/medidaprovisoria-746-22setembro-2016-783654-exposicaodemotivos-151127-pe.html> Acesso em: 18 set. 2017.

BRASIL. Lei n. 13.005, de 25 de junho de 2014. Aprova o Plano Nacional de Educação - PNE e dá outras providências. Diário Oficial da União, Brasília, DF, 26 
DOI: $10.12957 / \mathrm{e}-\mathrm{mosaicos} .2019 .46449$

jun 2014.

BRASIL. Conselho Nacional de Educação. Parecer CNE/CEB no 5, de 4 de maio de 2011. Trata das Diretrizes Curriculares Nacionais para o Ensino Médio. Brasília: Ministério da Educação, 2011.

CASTEL, Robert. As metamorfoses da questão social: uma crônica do salário. Petrópolis, RJ: Vozes, 1998.

CAVALIERI, Ana M. Escolas de Tempo Integral versus Alunos em Tempo Integral. Em Aberto, Brasília, v. 22, n. 80, abr. 2009. p. 51-64.

CUNHA, Luiz A. Ensino Médio: atalho para o passado. Educação \& Sociedade. Campinas, v.38, n.139, abr/jun 2017. p.373-384.

FERRETTI, Celso J. A reforma do ensino médio: desafios à educação profissional. Holos, Ano 34, Vol. 04.

FERRETI, Celso J.; SILVA. Mônica R. Reforma do ensino médio no contexto da medida provisória no 746/2016: estado, currículo e disputas por hegemonia. Educação \& Sociedade. Campinas, v.38, n 0 139, abr/jun 2017, p. 385-404.

FRIGOTTO, Gaudêncio; FERREIRA, Sônia. M. Cultura autoritária, ultraconservadorismo, fundamentalismo religioso e o controle da educação básica pública. Trabalho Necessário. V.17, n.32, jan-abr 2019.

. A produtividade da escola improdutiva. 6. ed, São Paulo: Cortez, 2001.

GRAMSCI, Antônio. Os Intelectuais Orgânicos e a Organização da Cultura. 9a ed., Rio de Janeiro: Civilização Brasileira, 1995.

IBGE. Síntese de indicadores Sociais: uma análise das condições de vida da população brasileira 2017. Rio de Janeiro: IBGE, Coordenação de População e Indicadores Sociais, 2017. Disponível em:

<https://biblioteca.ibge.gov.br/visualizacao/livros/liv101459.pdf> Acesso em: 16 mai. 2018.

JUNCKES, Cris R. G. Educação integral, ampliação do tempo escolar e formação da criança: possíveis relações. UFPR: XI Anped Sul, Curitiba, 2016.

KUENZER, ACACIA Z. A educação profissional nos anos 2000: a dimensão subordinada das políticas de inclusão. Educação \& Sociedade. Campinas, vol. 27, n. 96 - Especial, out 2006. p. 877-910. 
DOI: $10.12957 /$ e-mosaicos.2019.46449

LEVITSKY, Steven; ZIBLATT, Daniel. Como as democracias morrem? Tradução Renato Aguiar. 1. Ed. Rio de Janeiro: Zahar, 2018.

MARX, K. O Capital: crítica da economia política. 3a edição, São Paulo: Nova Cultural, 1988.

MÉSZAROS, István. A educação para além do capital. 2. ed. São Paulo: Boitempo, 2014.

MOTTA, Vânia C .; FRIGOTTO, Gaudêncio. Por que a urgência da reforma do ensino médio? Medida provisória no 746/2016 (Lei no 13.417/2017). Educação \& Sociedade. Campinas, v.38, no 139, abr-jun 2017. p. 355-372.

SILVA, Karen C. J. R. da; BOUTIN, Aldimara Catarina. Novo ensino médio e educação integral: contextos, conceitos e polêmicas sobre a reforma. Educação. Santa Maria, v. 43, no 3, jul/set 2018. p. 521-534.

SILVA, K. N. P.; SILVA, J. A. de A. da. Accountability e intensificação do trabalho docente no Ensino Médio Integral de Pernambuco. Práxis Educativa. Ponta Grossa, v. 9, n. 1, p. 117-140, jan.-jun. 2014.

SILVA, Mariléia Maria da. Inserção profissional de jovens: o circuito fechado da precarização In: Trabalho Educação. Belo Horizonte: FaE/UFMG, v. 23, n. 3 set./dez, 2014, p 177-194.

Recebido em 04 de novembro de 2019

Aceito em 04 de dezembro de 2019

A e-Mosaicos Revista Multidisciplinar de Ensino, Pesquisa, Extensão e Cultura do Instituto de Aplicação Fernando Rodrigues da Silveira (CAp-UERJ) está licenciada com uma Licença Creative Commons - Atribuição-NãoComercial 4.0 Internacional.

Os direitos autorais de todos os trabalhos publicados na revista pertencem ao(s) seu(s) autor(es) e coautor(es), com o direito de primeira publicação cedido à e-Mosaicos.

Os artigos publicados são de acesso público, de uso gratuito, com atribuição de autoria obrigatória, para aplicações de finalidade educacional e não-comercial, de acordo com o modelo de licenciamento Creative Commons adotado pela revista. 